\title{
Narcotráfico y desarrollo político \\ en el México contemporáneo ${ }^{1}$
}

\author{
Drug trafficking and political development \\ in contemporary Mexico
}

Sara Núñez de Prado Clavell ${ }^{2}$

Resumen: Este artículo presenta el narcotráfico como un problema multidimensional, ya que afecta a una amplia gama de delitos y perturba la convivencia social a la vez que atenta contra las raíces del propio Estado, debilitando las estructuras de poder, corrompiéndolas y haciendo cada vez más difícil la separación entre la legalidad y la industria de la droga. A partir de esta premisa se analiza la evolución del narcotráfico en México y la relación existente entre él y el poder político, así como su efecto en cuestiones como los derechos humanos. Finalmente se ofrecen algunas reflexiones sobre las posibles soluciones.

Palabras clave: México, Narcotráfico, Derechos Humanos, Corrupción, Gobierno.

Abstract: This article presents drug trafficking as a multidimensional problem in that it affects a wide range of crimes and disturbs social coexistence, and threatens the roots of the country, weakening and corrupting power structures as well as making the separation between the legality and the drug industry increasingly difficult. Here I analyze the evolution of drug trafficking in Mexico and the existing relation between it and the political power as well as its effect in such issues as human rights. Finally, some reflections on the possible solutions are offered.

Keywords: Mexico, Drug trafficking, Human rights, corruption, government.

Doi: https://doi.org/10.24215/23142766e078

${ }^{1}$ Recibido el 08/10/2019. Aceptado el 30/11/2019

${ }^{2}$ Licenciada en Ciencias de la Información por la UCM y doctora por la misma universidad desde 1992. Licenciada en Geografía e Historia (especialidad Historia Contemporánea), Licenciada en Derecho y Diplomada en Defensa Nacional por el CESEDEN y Maestria en Altos Estudios Internacionales. Profesora titular de Historia del Mundo Actual en la Universidad Rey Juan Carlos. E-mail:sara.clavell@urjc.es

${ }^{3}$ La autora forma parte del Proyecto de Investigación «Europeísmo y redes transatlánticas en los siglos XX y XXI»: PGC2018-095884-B-C22 (Ministerio de Ciencia, Innovación y Universidades/UE-FEDER). 
En mayo de 2003 en Madrid, Moisés Naim, director de Foreign Policy, advertía sobre el riesgo de que la excesiva atención que se estaba dando al terrorismo internacional pudiera dejar en un segundo plano la lucha contra lo que denominaba "las otras cinco guerras de la globalización", guerras que, según él, los gobiernos estaban perdiendo. Naim se refería al narcotráfico, el contrabando de armas, la inmigración ilegal, la piratería intelectual y el lavado de dinero. Ya en aquel entonces, en su intervención, el politólogo venezolano ponía de manifiesto que "el narcotráfico mueve al año, según la ONU, 400.000 millones de dólares, es decir, el $8 \%$ del comercio mundial"4. Para 2018, según la Oficina contra las Drogas y el Delito de las Naciones Unidas (UNODC), este mercado ha generado 650.000 millones de dólares de ganancias anuales ${ }^{5}$. Por ejemplo, según El País, durante un mismo año "el precio del kilo de cocaína se puede multiplicar desde 1.300 dólares en la selva de Colombia hasta 27.000 en Estados Unidos, 53.000 en Europa y 200.000 en Australia" 6.

Naim no se equivocaba y en la actualidad el narcotráfico es uno de los problemas más graves, aunque no es un fenómeno nuevo, ya que echa sus raíces en la historia. No hay más que recordar las guerras del opio que se dieron en el siglo XIX y que enfrentaron a China y Gran Bretaña precisamente por la comercialización de este producto, ya que mientras los chinos querían prohibirlo, los británicos querían extender el mercado ${ }^{7}$.

Hoy la situación ha variado mucho, no solo con relación al siglo XIX sino también desde los años setenta u ochenta del siglo XX, época en la que el narcotráfico comienza a considerarse una cuestión que traspasa fronteras ${ }^{8}$. Es una realidad que el mapa del narcotráfico ha cambiado considerablemente a lo largo del tiempo, sobre todo en un país como México, objeto de nuestro estudio. Es concretamente 2006 la fecha que marca un antes y un después en este tema. Ese año el gobierno del presidente Vicente Calderón decidió iniciar una lucha sin cuartel contra los cárteles de la droga que, lejos de terminar con el problema, lo que hizo fue redimensionarlo y trasladarlo a una esfera superior de violencia.

\footnotetext{
${ }^{4}$ Luis Prados, "Moisés Naím advierte contra las "cinco guerras de la globalización"”, El País, 22-5-2003, Madrid, España,https://elpais.com/diario/2003/05/22/internacional/1053554419_850215.html (Fecha de consulta: 18 de marzo de 2018).

${ }^{5}$ Carmen Merino, "Drogas: ¿Sabes cuánto dinero mueve el narcotráfico en el mundo?", La República, 4-112018,Lima, Perú,https://larepublica.pe/economia/1350878-narcotrafico-dinero-mueve-mundo, (Fecha de consulta: 18 de marzo de 2018).

${ }^{6}$ Guillermo de la Dehesa, "El gran negocio del narcotráfico", El País, 9-02-2018, Madrid, España, https://elpais.com/economia/2018/02/08/actualidad/1518088355 153674.html(Fecha de consulta: 18 de marzo de 2018).

${ }^{7}$ Fueron los chinos los que a través del puerto mexicano de Mazatlán llevaron el opio al continente americano y lo desarrollaron en la zona de Sinaloa ya que allí el clima era propicio. Desde esta región pasaría a Estados Unidos, por lo que ellos fueron los que iniciaron las primeras rutas internacionales del narcotráfico.

8 Un informe de la DEA (Agencia Antidrogas Estadounidense), publicado en 2015, pone de manifiesto las relaciones entre los cárteles mexicanos y colombianos, ya que las TCO (Organizaciones Transnacionales) colombianas suministran, sobre todo, cantidades al por mayor de cocaína y heroína a los mercados de drogas del noreste, siendo los traficantes colombianos los que proporcionan estas sustancias a las organizaciones mexicanas y dominicanas, que las que se dedican al transporte y distribución. Además, aunque antes del 2000 eran los colombianos los que dominaban los mercados de cocaína y heroína en el Medio Oeste y en la costa este estadounidense, ahora son los mexicanos los que están controlando ese mercado. Drug Enforcement Administration (DEA), (2015), "NationalDrugThreatAssessment",

https://www.dea.gov/docs/2015\%20NDTA\%20Report.pdf (Fecha de consulta: 18 de marzo de 2018).
} 
El presente trabajo tiene como objetivo, además de realizar un panorama general de la evolución del narcotráfico en el país azteca y ayudar a explicar la situación actual, poner de manifiesto que este problema echa sus raíces directamente en la realidad mexicana, por lo que, por mucho que se avance en ciertos aspectos, como puede ser el legislativo, mientras no se busquen soluciones imaginativas y de tipo educativo que puedan cambiar a la sociedad en su conjunto, éste será un problema que no solo pervivirá, sino que se permeará, cada vez más, a todos los estratos y grupos sociales, incluidas las autoridades. Como dice el Informe de la UNODC para el 2019,

donde hay vulnerabilidad, hay actividad delictiva. Es fundamental hacer frente a ambos elementos de manera equilibrada e integral mediante respuestas de justicia penal que se centren en la salud y se basen en los derechos. Los niveles récord de producción de cocaína y opiáceos de los últimos dos años, unidos a la expansión del mercado de las drogas sintéticas como el fentanilo y sus análogos fabricados ilícitamente, exigen mayores esfuerzos por parte de las fuerzas del orden. La cooperación internacional sigue siendo una herramienta crucial para combatir con éxito el tráfico de drogas $^{9}$.

\section{Multidimensionalidad del narcotráfico}

La definición de narcotráfico hace referencia a la existencia de una industria ilegal, de ámbito mundial, que consiste en el cultivo, procesamiento, elaboración, distribución y venta de sustancias ilegales o drogas.

El narcotráfico, por sus dimensiones y características, tiene relación directa con otro tipo de delitos, como el tráfico de armas, el tráfico de personas, el secuestro, el asesinato, la tortura, el blanqueo de capitales y la corrupción, entre otros. Es una actividad propia del crimen organizado que incursiona en las esferas del Estado y que tiende sus redes a lo largo de la sociedad, tanto en las clases altas como en las medias y bajas ${ }^{10}$.

En donde que sí existe una clara diferenciación es entre países productores y los consumidores. Los primeros se ubican fundamentalmente en Oriente Medio, Asia y América Latina, entre los que se destacan Colombia, México, Honduras, Bolivia, Afganistán, Vietnam o Camboya; mientras que los segundos son Estados Unidos y los países europeos. Cuando la droga llega a éstos, los precios, como se ha apuntado más arriba, ya se han multiplicado varias veces. En estos países consumidores es por lo que también desde los poderes políticos se han puesto en marcha acciones especiales para luchar contra el narcotráfico. Ahora bien, ello no quiere decir que en los países productores no se consuma droga. Pero lo que suele

\footnotetext{
${ }^{9}$ Disponible el ExecutiveSummary en https://wdr.unodc.org/wdr2019/en/exsum.html(Fecha de consulta: 30 de agosto de 2019).

${ }^{10}$ Sobre el tema del narcotráfico hay mucho material publicado. Entre los más interesantes y más directamente relacionados con la cuestión mexicana, puede citarse el de Norberto Emmerich (2015), Geopolítica del narcotráfico en América Latina, México: Instituto de Administración Pública del Estado de México. También, Luis Jorge Garay Salamanca (2012), Narcotráfico, corrupción y Estados: cómo las redes ilícitas han reconfigurado las instituciones en Colombia, Guatemala y México, México: RamdomHouseMondadori. O el de Alain Labrousse (2011), Geopolítica de las drogas, Buenos Aires: Marea Editorial.
} 
distinguirlos de los llamados "consumidores" es el tipo de droga. Así, mientras que en los desarrollados el consumo más habitual es el de la cocaína, marihuana, hachís u otras drogas de diseño (con aumento en este aspecto progresivamente durante los últimos años), en los productores lo habitual es consumir mezclas caseras de pegamento, pasta base o paco (pasta base de cocaína de bajo precio). Por tanto, la producción y subsiguiente comercialización suele darse en países subdesarrollados y con una escasa presencia real del Estado, es decir, en lugares en donde la población encuentra una salida fácil para sobrevivir con el narcotráfico, a la vez que los "señores de la droga" aprovechan los vacíos de poder existentes para llenarlos con su propia ley. Asimismo, ante un estado débil la posibilidad de infiltrase en las redes del poder se hace más fácil, desarrollándose así altas dosis de corrupción que cada vez dificultan más la lucha contra el narcotráfico.

Como explica David Held (1997), el problema va más allá de una simple distribución desigual de los recursos, pues lo que realmente pasa es que se niegan un conjunto de derechos, sobre todo económicos y sociales, que atentan directamente sobre la base de la democracia. Es esa exclusión social y la imposibilidad de integrase en el mercado de trabajo lo que está en la raíz de la frustración de amplios sectores sociales que encuentran su camino de salvación a través del mundo narco y el tráfico de drogas, ya que con esta actividad consiguen dinero suficiente para poder satisfacer las necesidades de consumo que la propia sociedad en la que viven, aunque los mantiene al margen, les ha generado. Así, la existencia de grupos sociales desfavorecidos, con pocas posibilidades de progreso, problemas de marginación, dificultades de inclusión social, etc. facilita que los cárteles puedan reclutar verdaderos ejércitos de fieles colaboradores que sobreviven gracias al dinero que les proporciona el tráfico de drogas. Como afirma Orihuela Ochoa,

narcotráfico, en su acepción más básica o general, es un campo de prácticas ilegales que involucra a una multiplicidad de actores institucionales y/o criminales, y cuyo corazón no es la droga (aun cuando tiene una relación tangencial), sino la gobernabilidad (interacción entre el Estado y actores no estatales; construcción del orden social) y los mercados (arena en la que discurren las transacciones de procesos-bienes-servicios y la apropiación de plusvalías). Ergo, la causa decisiva de la situación delincuencial (narcotráfico) es la situación económico-política ${ }^{11}$.

Consecuencia de todo lo anterior es por lo que hablamos de un problema multidimensional. No sólo porque abarca un amplio panorama de delitos ligados al tráfico de la droga, sino también porque atenta contra las raíces del propio Estado, debilitando las estructuras de poder, corrompiéndolas y haciendo cada vez más difícil la separación entre la legalidad y el narcotráfico. Hay que tener en cuenta que "debido a su capacidad para corromper y amenazar a los funcionarios públicos, los narcotraficantes se han convertido en la ley de facto en muchas ciudades mexicanas" (Freeman, 2006: 2).

\footnotetext{
${ }^{11}$ Arsinoé Orihuela Ochoa, “México. La otra historia del narcotráfico (I)”, Tercera Información, 5-12-2017, Madrid, España,http://www.tercerainformacion.es/opinion/opinion/2017/12/05/mexico-la-otra-historia-delnarcotrafico-i(Fecha de consulta: 18 de marzo de 2018).
} 
México no es el único ejemplo que podríamos estudiar en este tema, pero sí, quizás junto con Colombia, sea el más conocido y el más representativo ${ }^{12}$. Por ejemplo, en este país se ve claramente por qué es un problema multidimensional: el vacío de poder en la República mexicana se siente fundamentalmente en la zona fronteriza del Norte y en las zonas costeras, que son los lugares que más han sufrido la violencia del narcotráfico, pues la autoridad estatal ha sido sustituida por las impuestas por los ejércitos de los distintos cárteles. A la vez, la capital y lugares aledaños, donde los cárteles están infiltrados en las más altas esferas del poder, son los sitios en los que los índices de violencia son menores, pero no por ello lo es la presencia "del narco".

\section{Legislación básica contra el narcotráfico en México}

La Constitución mexicana establece en su artículo 89, fracción VI, que es al Presidente de la República a quien le confiere de manera exclusiva el mandato de preservar la Seguridad Nacional. Asimismo, el artículo 25 dice que le corresponde también dirigir el desarrollo nacional para garantizar que sea integral y sustentable, que fortalezca la soberanía de la Nación y su régimen democrático.

Por su parte, el artículo 7 de la Ley de Seguridad Nacional exige que sea el Plan Nacional de Desarrollo y su Programa los que definan los temas en esta materia. Asimismo, el Reglamento para la Coordinación de Acciones Ejecutivas en Materia de Seguridad Nacional en sus artículos 5, 6 y 7 establece que los temas de Seguridad Nacional se atenderán con una visión estratégica, integral, amplia y de largo alcance.

La base de la legislación contra las drogas, además del Código Penal Federal, reformado en 1994 junto con el Código Federal de Procedimientos Penales, es la Ley General de Salud, de 1984, modificada en 2009 mediante un decreto que se conoce popularmente como Ley de Narcomenudeo, que pretende combatir el comercio de la droga al por menor a la vez que marca las cantidades exentas de delito por considerarse para consumo propio. Estas están establecidas en 5 gramos de cannabis, 2 de opio, medio de cocaína, 50 miligramos de heroína o 40 de metanfetamina. Esta ley causó polémica en su momento, pues fue vista como una parte de "un paquete relacionado con la seguridad pública nacional, y en tal entorno se ha convertido en una extensión de la pugna política entre el gobierno federal (PAN) y los gobiernos locales de partidos políticos de la oposición" (Zamudio Anglés, 2011). Por su parte, la reforma del Código Federal Penal de 1994 aumentó la cuantía de las penas por producción, transporte, tráfico, comercio y suministro, situándolas ahora entre 10 y 25 años. Las penas por el cultivo disminuyeron. También hay que contemplar la Ley Federal contra la Delincuencia Organizada, aprobada en 1996, que marcó un hito pues elevó considerablemente las penas cuando el delito se cometía inserto en una asociación delictiva. Asimismo, puso en marcha la figura del arraigo ${ }^{13}$, que permite mantener detenido a un sospe-

\footnotetext{
12 Es muy interesante en este sentido, consultar la obra de Jorge Fernández Menéndez (2008), Las FARC en México: de la política al narcotráfico, Ciudad de México: Aguilar.

${ }^{13}$ Esta figura fue incorporadaa la Constitución en 2008. La idea era prever que personas que se considerasen sospechosas de pertenecer al narcotráfico, no tuvieran posibilidad de delinquir ya que se les privaba de la libertad. Hubo protestas pues se decía que atentaba contra el derecho a libertad personal y a la presunción
} 
choso hasta 80 días, sin necesidad de acusación formal, siempre que el delito que presumiblemente se le impute esté relacionado con la delincuencia organizada. En 2008 entró en vigor un nuevo Sistema Penal Acusatorio. En 2016 sobre esta cuestión, el presidente Peña Nieto dijo que la idea que había animado a la aprobación de ese nuevo sistema había sido potenciar "la prevención, la investigación y la sanción del delito, así como en la construcción y la ejecución de un marco normativo sólido para asegurar en todo el territorio nacional una justicia pronta, transparente, expedita y eficaz" (Peña Nieto, 2016).

En 2009, se aprobó la Ley General del Sistema Nacional de Seguridad Pública, que insistía en la necesidad de que los tres órdenes de gobierno (federal, estatal y municipal añadiéndose el Distrito Federal) colaborasen estrechamente, y un año después la Ley General para Prevenir y Sancionar los Delitos en materia de Secuestro, que fue reformada en 2016. Este delito se declaraba imprescriptible.

En abril de 2017 la Cámara de los Diputados votó una nueva reforma a la Ley General de Salud y al Código Penal Federal con el fin de permitir el uso con fines terapéuticos de la marihuana ${ }^{14}$.

\section{El narcotráfico como problema actual ${ }^{15}$}

Sin intentar hacer una historia exhaustiva del narcotráfico mexicano, puede decirse que el origen moderno del problema se remonta a los años 40 del siglo $X^{16}$. En ese momento aumentó el consumo de heroína en Estados Unidos, lo que, unido a la práctica, que no teórica, tolerancia que existía en México al cultivo de la droga, se iniciaron las primeras alianzas sólidas entre sus cultivadores (organizaciones criminales) y los políticos locales. De esta forma, comienzan a participar en el narcotráfico no solo los propios narcotraficantes, sino también políticos, jueces, policías y militares, quienes veían en esta actividad una manera de incrementar sus ingresos a cambio de muy poco riesgo. El entramado de lo que iban a ser las grandes redes del mercado mexicano comenzaba a trazarse ya. Así, entre la década

de inocencia. También se hacía referencia a la posibilidad de mantener las garantías de un proceso justo o el derecho a un recurso efectivo.

${ }^{14}$ Sobre la evaluación de la legislación mexicana en esta materia, es interesante el trabajo (resumen de su tesis de maestría) de Ana Paula Hernández (2010), “Legislación de drogas y situación carcelaria en México", en, ColettaYoungers y PienMetaal (eds.), Sistemas sobrecargados. Leyes de drogas y cárceles en América Latina, Washington: Transnacional Instittute. Muy crítica es la obra de Óscar Baez Soto (2013), Las deficiencias jurídicas en la ofensiva contra la delincuencia organizada, Ciudad de México: Ubijus Ed.

${ }^{15}$ Sobre la historia del narcotráfico en México, es clásico el trabajo de Luis Astorga (2005), El siglo de las drogas, Ciudad de México: Plaza y Janés; y también el de loan Grillo (2012), El Narco: InsideMexico's Criminal Insurgence, Ciudad de México: Tendencia Editores. Astorga establece las siguientes etapas para el narcotráfico mexicano: 1914-1947, 1947-1985, 1985-2000 y la última, que inicia en el 2000. Interesante asimismo el libro de Guillermo Valdés Castellanos (2013), Historia del narcotráfico en México: apuntes para entender al crimen organizado y la violencia, Ciudad de México: Aguilar.

${ }^{16}$ Con anterioridad a estos años existía un mercado de drogas clandestino cuando México prohibió el cultivo de amapola y marihuana. Es lo que se conoce como las primeras leyes prohibicionistas. E incluso se puede hablar de un mercado de heroína controlado por los chinos que empleaban mexicanos para la venta. Con el tiempo, los mexicanos desplazarían a los chinos, según el negocio fue aumentando. No obstante, no se conformaron entonces organizaciones criminales de amplias dimensiones, aunque sí se utilizaba ya la compra de autoridades locales para mover el negocio con impunidad y el uso de la violencia para mantener el control. 
de los cuarenta y los ochenta se forman los primeros grandes cárteles en los que, más allá de los propios narcotraficantes, tendrán un papel primordial, más que los políticos, las autoridades militares y policiales. Este proceso se ve favorecido por la centralización del poder político, la existencia de un partido mayoritario, el PRI, instalado de manera permanente en el poder y el hecho de que la necesidad de distribución del producto llevase a que los cárteles se expandieran por otros lugares del territorio, creándose así poderes locales que intentaban afianzar su autoridad constituyendo y delimitando sus propias zonas de influencia.

A mediados de este periodo, concretamente a finales de la década de los sesenta, la presidencia de Nixon estableció una relación entre la lucha por los derechos civiles, las manifestaciones pacifistas contra Vietnam y el consumo de drogas, lo que llevó al gobierno estadounidense a pedir a su vecino del Sur que intensificase su lucha contra el narcotráfico. Como consecuencia de ello, como ya se apuntó, comenzó la cooperación entre ambos gobiernos para entablar la batalla contra la droga, lo que marca la llegada de los primeros asesores, las primeras armas y las primeras cantidades de dinero norteamericano a México con el fin de financiar la lucha contra las drogas ${ }^{17}$. En 1969 la administración estadounidense puso en marcha la "Operación Intercepción", con el fin de controlar los vehículos y personas que transitasen por la frontera ${ }^{18}$. Ya desde entonces se inició la dualidad que ha caracterizado al gobierno mexicano en este tema: permisividad en la producción y colaboración (más o menos comprometida) en el combate contra el narcotráfico.

Ahora bien, hay que señalar que las relaciones para el combate al tráfico de drogas entre México y Estados Unidos no empezaron ese año. De hecho, fue en1930 cuando se produjeron los primeros canjes de notas diplomáticas.

Años después, en 1975, el gobierno de México puso en marcha una campaña encaminada a erradicar el cultivo de marihuana y adormidera. Nacía la Operación Cóndor, que tendría vigencia hasta 1978. Según los informes oficiales, entre 1970 y 1976 "se destruyeron más de 65.000 plantíos de adormidera y más de 46.000 de marihuana, 4.980 de opio, 1.142 kgs. de heroína, 76.898 kgs. de morfina, 1.180 kgs. de cocaína, 1.100 kgs. de hachis, más de 92 millones de comprimidos conteniendo sustancias psicotrópicas y 3.152 .353 kgs. de marihuana seca. Se detuvo a más de 18.000 individuos, de los que por lo menos 2.000 eran extranjeros" ${ }^{\prime 19}$. Asimismo, el periódico El Sol de México, relata que

del 1 de septiembre de 1975 al 31 de agosto de 1976, la policía judicial y el ejército habían destruido 21.405 parcelas de adormidera, mientras que el año anterior habían sido 13.580. En ese mismo periodo, eliminaron 16.686 parcelas de marihuana, frente a 6.762 de los doce meses precedentes. Por el lado de la interdicción y aprehensión de delincuentes, las cosas no eran

\footnotetext{
${ }^{17}$ Sobre las relaciones entre ambos países en materia de narcotráfico puede consultarse el trabajo de Carmen Boullosa y Mike Wallace (2015), A narco history: howtheUnitedStates and Mexicojointlycreatedthe "Mexicandrugwar", Nueva York: OR Books. También tiene interés el trabajo de Miguel Ruiz-Cabanas (1999), "Intereses contradictorios y mecanismos de cooperación: el caso del narcotráfico en las relaciones mexicano-estadounidenses", en Olga Pellicer y Rafael Fernández de Castro (eds.), México y Estados Unidos: las rutas de cooperación, Ciudad de México: SRE-ITAM.

${ }^{18}$ Se había llegado a un acuerdo previo de cooperación en 1959 que puede considerarse el antecedente del de 1969.

${ }^{19}$ Enrique Florescano (Ed.), “La Operación Cóndor. Recuento mínimo”, Nexos, 1-05- 1978, Ciudad de México, México, https://www.nexos.com.mx/?p=3120 (Fecha de consulta: 18 de marzo de 2018).
} 
muy diferentes. Del periodo 1974-1975 al 1975-1976, el número de aprehensiones aumentó de 2752 a 4 399. Además, se decomisaron 215 kilos de cocaína en tránsito y se desmantelaron 16 laboratorios donde se procesaban drogas. ${ }^{20}$

Esta etapa termina en la década de los 80, momento a partir del cual se entra en una nueva fase, debido a que cárteles que se habían formado en la anterior comienzan a dividirse. En estos años el cártel dominante era el llamado "de Sinaloa" o "de Guadalajara", pues tenía la sede en la capital jalisciense, desde donde controlaba a diversas pequeñas organizaciones. Estas, poco a poco, fueron adquiriendo más y más poder y comenzaron a disputar el territorio a los de Sinaloa. Paralelamente en 1985 ocurrió el secuestro y posterior asesinato en territorio mexicano del agente de la DEA, Enrique Camarena (Kiki), por parte del cártel de Sinaloa ${ }^{21}$. La respuesta de las autoridades intentó ser contundente y el resultado fue, no la desaparición del cártel como tal, sino su fragmentación definitiva ${ }^{22}$. Asimismo, este asesinato sacó a la luz la infiltración de los narcotraficantes en las instituciones del Estado, fundamentalmente en la Policía Judicial Federal, la Dirección Federal de Seguridad e incluso la Secretaría de Gobernación (SEGOB), que en los años siguientes sufriría una profunda reestructuración. Lo mismo ocurrió con la Dirección Federal de Seguridad, establecida en 1947, y con la Dirección de Investigaciones Políticas y Sociales, creada en 1967. Ambas desaparecieron y en su lugar apareció la Dirección General de Investigación y Seguridad Nacional23 ${ }^{23}$, implantada en 1985 por el presidente De la Madrid. Esta institución estaba, en teoría, libre de infiltraciones delictivas. Sin embargo, ni las policías locales, ni las procuradurías, ni la Policía Judicial Federal sufrieron cambios, con lo que los contactos con el narcotráfico se mantuvieron. Otro hecho que marca el cambio de etapa es la aparición de la cocaína en territorio mexicano, proveniente de Colombia ${ }^{24}$, lo que dará un nuevo aire al narcotráfico de estas tierras.

\footnotetext{
${ }^{20}$ Nidia Marín, "Operación Cóndor, el inicio de la guerra contra el narcotráfico", El Sol de México, 24-04- 2016, Ciudad de México, México, https://www.elsoldemexico.com.mx/mexico/Operaci\%C3\%B3n-C\%C3\%B3ndorel-inicio-de-la-guerra-contra-el-narcotr\%C3\%A1fico-170670.html (Fecha de consulta: 18 de marzo de 2018).

${ }^{21}$ Junto a Enrique-Kiki-Camarena también fue secuestrado y asesinado el piloto de la entonces Secretaría de Agricultura y Recursos Hidráulicos, Alfredo Zavala. Como curiosidad, señalar que en enero de 2017 un juez del estado de Jalisco condenó al fundador del cartel de Guadalajara, Ernesto Fonseca Carrillo -Don Neto-, actualmente en prisión, a pagar a los familiares de ambas víctimas la cantidad de 20.810 .000 pesos en concepto de indemnización. Ignacio Alzaga, "Juez ordena indemnizar a familiares de 'Kiki' Camarena”, Milenio, 13-01-2017, Monterrey, México, http://www.milenio.com/policia/kiki-camarena-don-neto-asesinato-deaagente-asesinado-cartel guadalajara_0 883711836.html (Fecha de consulta: 18 de marzo de 2018). Por este crimen, fueron detenidos Rafael Caro Quintero y Ernesto Fonseca Carrillo, dos sicarios del cártel. Y en 1989 también lo fue Miguel Ángel Félix Gallardo -El Padrino-, otro de los líderes del cártel. Este último fue condenado a 37 años de prisión como autor intelectual de los crímenes.
}

${ }^{22}$ Surgieron al menos siete grupos distintos: Ciudad Juárez, Tijuana, cártel del Golfo-Zetas, Los Valencia, La Familia Michoacana, cártel de Colima y el de Sinaloa que siguió funcionando en parte. Estos grupos siguieron rivalizando entre sí y aumentaron considerablemente el grado de violencia en sus actuaciones.

${ }^{23}$ Esta Dirección será el antecedente del Centro de Investigación y Seguridad Nacional (CISEN), una de las organizaciones, en teoría, más limpias del estado mexicano. Fue creada en 1989 por el presidente Salinas de Gortari.

${ }^{24}$ Los cárteles colombianos debían encontrar nuevas rutas para pasar la mercancía a Estados Unidos y el territorio mexicano parecía una opción muy conveniente. Así comenzó la alianza entre colombianos y aquellos grupos mexicanos que controlaban lugares estratégicos de paso. 
Los años que van de 1988 a 1994, en coincidenca con el mandato de Salinas de Gortari, fueron los años "dorados" para el narcotráfico en general, ello a pesar de que las acciones del gobierno parecían encaminadas a luchar contra él. En este sentido, el país vivió una dualidad llamativa. Por un lado, daba la impresión de que las autoridades se empeñaban en luchar contra el narcotráfico. Por ejemplo, se intensificó la colaboración internacional en estas cuestiones o se creó la Subprocuraduría de Investigación y Lucha contra el Narcotráfico. También México participó y suscribió (1989) la Convención contra el Tráfico llícito de Estupefacientes y Sustancias Sicotrópicas de Naciones Unidas, a la vez que en las noticias se podían leer una importante cantidad de éxitos de la policía y el ejército en su combate contra el narco: decomisos de grandes cantidades de droga y dinero, destrucción de la mercancía, etc. Pero, a pesar de todo ello, lo cierto es que algunos cárteles crecieron mucho, como el de Tijuana o el de los Arellano y sobre todo el de Juárez, que alcanzó cotas de poder muy altas. En estos años, incluso, se llegó a procesar al hermano del presidente Salinas, Raúl ${ }^{25}$, por enriquecimiento ilícito, aunque parece que nunca llegó a cumplir la sentencia impuesta.

La siguiente etapa inicia a partir de 1994, con el mandato de Ernesto Zedillo, el último presidente del PRI en los primeros setenta años de mandatos ininterrumpidos de este partido $^{26}$, y dura hasta 2006. Lo más llamativo de estos años fue el acuerdo que se firmó con Estados Unidos en 1997 para la cooperación en la lucha contra la droga. Pero lo cierto es que tampoco este gobierno estaba limpio. De hecho, no sólo también un hermano del presidente fue acusado de tener relaciones con el narcotráfico, sino que incluso se descubrió que el general que abanderaba la lucha contra las drogas y era el Director del Instituto Nacional para el Combate a las Drogas, Gutiérrez Rebollo, había tenido relaciones con el Cártel de Juárez. Además, una vez conocida su relación con el narcotráfico, el general Gutiérrez Rebollo también acusó al Secretario de Defensa Nacional de estar protegiendo a otros militares que estaban relacionados con el mismo cártel. Del mismo modo, a finales de la década, fue acusado de relaciones con el narcotráfico el gobernador del estado de Quintana Roo, Ernesto Villanueva Madrid, que antes de perder la inmunidad del cargo decidió huir y fue apresado en 2001, condenado a prisión, extraditado en 2010 a Estados Unidos para ser juzgado por blanqueo de dinero y vuelto a México en 2017, después de cumplida la pena, para ser juzgado por los delitos de delincuencia organizada, asociación delictiva e intimidación ${ }^{27}$.

El cambio de partido en el poder, en el año 2000, no supuso en un primer momento ninguna innovación en la lucha contra las drogas. Desde Los Pinos, el presidente Fox seguía

\footnotetext{
${ }^{25}$ Siempre se pensó que también los tenía el propio presidente, sobre todo con el Cártel del Golfo, pero esto no se pudo probar nunca.

${ }^{26}$ Este periodo de los años 90 hacia delante está muy bien retratado en el trabajo de José Luis Solís (2013), "Neoliberalismo y crimen organizado en México: El surgimiento del Estado narco", Frontera Norte, México, v. 5, no 25, pp. 7-34. El autor se refiere a que "Se está de hecho ante el surgimiento en México de una nueva forma de Estado capitalista periférico, que hemos caracterizado como Estado narco, la cual se ha manifestado externamente (es decir, en tanto que forma fenoménica y, por lo tanto, específica del Estado mexicano) en la instauración de un régimen político neoliberal tecnocrático con una fuerte presencia de representantes del crimen organizado en sus distintos gobiernos, en la economía y las finanzas. Este fenómeno está indisolublemente vinculado con la emergencia, en los años noventa, de un nuevo régimen de acumulación, fuertemente trasnacionalizado y volcado hacia el exterior, con una participación creciente del narcotráfico como una de las fracciones más dinámicas y rentables del capital pero, desde luego, no la más importante" (pág. 8 y 9).

${ }^{27}$ Excelsior, "Mario Villanueva Madrid, los delitos que lo llevaron a prisión”, 16-01-2017, Ciudad de México, México, http://www.excelsior.com.mx/nacional/2017/01/16/1139886 (Fecha de consulta: 18 de marzo de 2018).
} 
presumiendo de la cantidad de droga que se decomisaba, del alto número de hectáreas de cultivo que habían sido destruidas y del número importante de capos que iban siendo detenidos o abatidos. De hecho, puso en marcha un programa denominado "México Seguro" (OMS) como estrategia de lucha contra la droga ${ }^{28}$. Ciertamente bajo este programa se llevaron a cabo diversas y variadas acciones, pero en la otra cara de la moneda se mantenía la reacción habitual: a capo desaparecido, capo sustituido por otro de segundo nivel que, generalmente, era más violento que el anterior, ya que tenía que "hacerse respetar" para conseguir el poder. De esta forma, aunque se debilitaron los cárteles tradicionales, surgieron otros nuevos, como Los Zetas o la Familia Michoacana, que les disputaban el territorio a los primeros. Un escándalo muy sonado durante el mandato de Fox fue, en 2001, la huida de una cárcel de máxima seguridad mexicana de "El Chapo" Guzmán ${ }^{29}$, lo que puso de manifiesto la corrupción que existía entre los funcionarios de prisiones y la posibilidad real de que desde la cárcel los narcos siguieran manteniendo vivo su poder y a sus organizaciones. Como explica Laurie Freeman (2006:11), el OMS fracasó en sus objetivos, ya que "lejos de reducir la narcoviolencia y la corrupción dentro de la policía en Nuevo Laredo, ambas parecen estar incrementándose. Se cree quelos cárteles de droga han infiltrado a todas las fuerzas de seguridad de la ciudad, con algunos apoyando al cártel del Golfo y otros trabajando para sus rivales de Sinaloa".

En estos años también hubo un cambio importante que rediseñó el narcotráfico en México. Desde la década de los 80 , cuando el país azteca se convirtió en ruta de paso de la cocaína colombiana, el transporte de la mercancía se había pagado con dinero en efectivo. Pero, cuando en los 90 los cárteles colombianos empezaron a tener problemas de liquidez, el pago comenzó a realizarse en especie. Entonces, el transportista mexicano que cobraba en coca, pasó a ser también traficante con el fin de convertirla en dinero. A ello hay que añadir, también, el hecho de que como consecuencia de los atentados del 2001 se dificultó mucho el paso de la droga a Estados Unidos, por lo que los mexicanos hubieron de incrementar el negocio en suelo propio, potenciando el consumo de la droga con el fin de ampliar el mercado nacional.

El siguiente periodo abarca desde el 2006 a la actualidad, aunque en los últimos tiempos ha habido algunos cambios que hay que señalar, aunque probablemente es aún pronto

\footnotetext{
${ }^{28}$ Ante el aumento de la violencia en la frontera, el alcalde de Nuevo Laredo nombró a un hombre de negocios conocido por su honradez, Alejandro Domínguez, para que ejerciese de jefe de la policía de la ciudad. El primer mensaje que Domínguez mandó fue que no negociaría con los cárteles. La respuesta de éstos fue asesinarlo el primer día que acudió a trabajar.

${ }^{29}$ El Chapo fue un fantasma durante muchos años, hasta que las investigaciones sobre el asesinato en elaeropuerto de Guadalajara del Cardenal Posada Ocampo le pusieron cara y nombre. Esta investigación también sacó a la luz la implicación de muchas autoridades con el narcotráfico. El escándalo llegó incluso hasta el secretario particular del Presidente de la República. Finalmente, El Chapo fue detenido en 1993 y condenado a 20 años de cárcel. Pero ya bajo el mandato de Fox, en 2001, consiguió escaparse de la cárcel de Puente Grande (Jalisco) con ayuda de los funcionarios de prisiones. Permaneció huido durante 13 años en losque el Cártel de Sinaloa creció y se afianzó en el mercado internacional. Según fuentes de la prensa, en esos años tuvo presencia en más de 50 países y controló en torno al $35 \%$ de toda la marihuana y cocaína que se movía en el mundo. En 2014 fue nuevamente capturado en Mazatlán, Sinaloa. De nuevo, volvió a huir de la cárcel en 2015 y una vez más fue capturado en 2016 y ese mismo año extraditado a Estados Unidos. Noticieros Televisa, "Las fugas de Joaquín 'El Chapo' Guzmán", Televisa, 19-01-2017, Ciudad de México, México, http://noticieros.televisa.com/historia/nacional/2017-01-19/las-fugas-de-joaquin-el-chapo-guzman/ (Fecha de consulta: 18 de marzo de 2018).
} 
para determinar fehacientemente el inicio de una nueva etapa. Volviendo a 2006, fue el presidente Vicente Calderón el que implicó al ejército y a la policía directamente en la lucha contra el narcotráfico. La razón de ello viene justificada por ese enfrentamiento entre cárteles por controlar el territorio que había llevado a que la violencia alcanzara cotas muy altas, pues los sicarios muchas veces se mataban entre ellos con el fin de debilitar al enemigo y controlar su territorio. Por ello, el presidente decidió emprender una lucha contra la droga (así la denominó) en la que no faltasen ni dinero ni efectivos de combate. Son años de debilidad extrema del gobierno, que intentó responder con la misma violencia a que era sometida la sociedad. El resultado, lejos de arrojar éxitos, sumió a México en una ola de muertes desconocida hasta entonces. Se calcula que esta guerra tuvo un saldo de más de 70.000 muertos, sin que ello mermara el poder real de los cárteles.

Pocos días después de alcanzar el poder, el 11 de diciembre de 2006, el presidente Calderón puso en marcha la "Operación Conjunta Michoacán". El Secretario de Gobernación, cuando la presentó a los medios, explicó que consistiría en "un despliegue de más de 5.000 efectivos para esta operación en la cual se desarrollarán actividades de erradicación de plantíos ilícitos, establecimiento de puestos de control para acotar el tráfico de enervantes en carreteras y caminos secundarios, ejecución de cateos y de órdenes de aprehensión, así como ubicación y desmantelamiento de puntos de venta de drogas"30.

También fruto de este intento de erradicar la violencia fue la "Iniciativa Mérida", un plan de lucha contra la droga entre México y Estados Unidos. Este plan era importante, entre otras cosas, porque ponía de manifiesto la responsabilidad conjunta de ambos estados en el tema del narcotráfico ${ }^{31}$. Como dijo en 2009 Carlos Rico, el diplomático mexicano que negoció el acuerdo: "Lo más importante de la Iniciativa Mérida es haber logrado un esquema de corresponsabilidad que nos vaya alejando de las nociones de asistencia extranjera para resolver un problema supuestamente nuestro, a una noción de cooperación para resolver un problema compartido para enfrentar un desafío común"32. Este acuerdo lo firmaron inicialmente los presidentes Calderón y Bush, pero se mantuvo vigente con Obama y Peña Nieto. En su origen, el Congreso de Estados Unidos asignó a este plan 2.300 millones de dólares. La Iniciativa después de la reforma a la que la sometieron los presidentes Obama y Peña Nieto, se enfocaba en cuatro puntos fundamentales: disminuir la capacidad operativa de los cárteles, institucionalizar la capacidad para mantener el estado de derecho, crear lo que se denominó la estructura fronteriza del siglo XXI, y formar comunidades fuertes y resilentes ${ }^{33}$. Con Donald Trump, aun-

\footnotetext{
${ }^{30}$ Presidencia de la República, (2016), "Anuncio sobre la Operación Michoacán”, http://calderon.presidencia.gob.mx/2006/12/anuncio-sobre-la-operacion-conjunta-michoacan/ (Fecha de consulta: 18 de marzo de 2018).

${ }^{31}$ Sobre la "Iniciativa Mérida" se puede consultar la obra de Perla Zoraida Barreda Vidal (2014), "La cooperación bilateral México-Estados Unidos contra la delincuencia organizada trasnacional en el marco de la Iniciativa Mérida", Revista IUS, Puebla, v. 8.

32 Expansión, "10 años de la iniciativa Mérida: Un recuento de la cooperación entre México y EEUU”, 4-092017, Ciudad de México, México,http://expansion.mx/nacional/2017/04/09/10-anos-de-la-iniciativa-merida-un-recuento-de-la-cooperacion-entre-mexico-y-eu (Fecha de consulta: 18 de marzo de 2018).

${ }^{33}$ Embajada y Consulados de Estados Unidos en México, (2018) “Iniciativa Mérida", https://mx.usembassy.gov/es/our-relationship-es/temas-bilaterales/iniciativa-merida/ (Fecha de consulta: 18 de marzo de 2018).
} 
que la iniciativa no ha desaparecido, sí se encuentra en peligro de extinción, entre otras razones porque el presidente estadounidense anunció un recorte del 30\% en las partidas destinadas a la cooperación exterior. Además, en este año 2019, el Presidente López Obrador ha manifestado su oposición a la continuidad de este plan de cooperación, manifestando que lo que México necesita no es envío de material bélico sino la creación de empleo ${ }^{34}$. Lo cierto es que no puede afirmarse que la Iniciativa Mérida haya obtenido resultados positivos considerables. Se calcula que en los años que ha estado vigente han sido más de 250.000 las muertes ocasionadas por el narcotráfico, alrededor de 40.000 los desaparecidos y un número muy considerable de desplazados. En lo que respecta al año 2019, parece que acabará siendo uno de los más violentos de las últimas décadas ${ }^{35}$.

Volviendo al desarrollo histórico, en la misma línea, en agosto de 2008 se suscribió el Acuerdo Nacional por la Seguridad, la Justicia y la Legalidad. Este Acuerdo implicaba a los tres poderes del estado, a los tres órdenes de gobierno, a los medios de comunicación y a distintos tipos de organizaciones públicas y privadas, como sindicatos o religiosas, así como a la sociedad civil. En él se suscribieron hasta 74 compromisos que abarcaban distintos aspectos sociales, políticos, económicos y jurídicos. Este Acuerdo se publicó en el Diario Oficial el 25 de agosto y en él se reconocía que

La sociedad mexicana se encuentra profundamente agraviada por la impunidad, la corrupción, la falta de coordinación entre las autoridades, así como por un ambiente de inseguridad y violencia. Muchas personas tienen miedo de transitar por las calles y plazas. La ciudadanía demanda de sus autoridades una respuesta inmediata y contundente que dé resultados en el corto, mediano y largo plazos. El Estado y la sociedad enfrentan una situación crítica debido tanto a la delincuencia común, que agravia cotidianamente a las familias, como al embate del crimen organizado, que es un fenómeno complejo, compuesto por un entramado de intereses y complicidades que trasciende fronteras. Superar esta situación no es una tarea fácil ni rápida. Al mismo tiempo, el Estado enfrenta el deterioro institucional de los organismos encargados de la seguridad pública, la procuración e impartición de justicia, como problemas desatendidos a lo largo de décadas.

Entre los compromisos, pueden citarse: “Depurar y fortalecer las instituciones de seguridad y procuración de justicia", "apoyar a las entidades federativas en el combate a los delitos más sensibles para la sociedad, de acuerdo con las competencias de cada orden de gobierno" $y$, en especial, "apoyar el fortalecimiento o en su caso la creación y formación de unidades estatales para el combate al secuestro" y "formular y emitir una estrategia nacional contra el lavado de dinero". Y en el orden preventivo, se hablaba de "fortalecer la atención a personas

\footnotetext{
${ }^{34}$ Jorge Alejandro Medellín, "México rechaza continuar con la Iniciativa Mérida de apoyo norteamericano contra el narcotráfico", 31-05-2019, Defensa.com, Ciudad de México, México,https://www.defensa.com/mexico/mexico-rechaza-continuar-iniciativa-merida-apoyo-norteamericano. (Fecha de consulta: 30 de agosto de 2019).

${ }^{35}$ Quien esté interesado en cifras más específicas puede consultar el artículo "México atraviesa el momento más sangriento de su historia" que analiza lo acontecido en 2017 y que fue publicado por el periódico El País el 22 de enero de 2018. El mismo periódico publicó un dossier muy completo referido al narcotráfico en México titulado "Año 11: la guerra contra el narco" (https://elpais.com/especiales/2016/guerra-narcotraficomexico/).
} 
con problemas de adicciones" y "dar apoyo a organizaciones de la sociedad civil dedicadas a la rehabilitación de personas con adicciones". También, "fortalecer el Programa de Rescate de Espacios Públicos" o de "fortalecer el Programa Escuela Segura". ${ }^{36}$

Cinco años después de su aprobación, el periódico Excelsior hacia el siguiente balance:

A casi cinco años de su firma, el Acuerdo Nacional por la Seguridad, la Justicia y la Legalidad registra resultados lentos y compromisos a medias en, al menos, 19 de los 74 puntos respaldados por los gobiernos federal, estatales, municipales y sociedad civil". Añadiendo que "la mayoría de los compromisos no cumplidos provienen de los gobiernos estatales y municipales ${ }^{37}$.

El anterior presidente, Enrique Peña Nieto, del PRI, partido que volvió al poder después de doce años de ausencia, siguió más o menos la misma política que su antecesor, con lo que la violencia realmente no se redujo. Además, fueron bastantes las voces que se refirieron a que existió una política por parte del gobierno priista de silenciar lo más posible las muertes, con el fin de dar una imagen de éxito en la lucha contra el narcotráfico. El gobierno siempre ha negado esta afirmación.

Lo cierto es que no existen cifras exactas sobre estas cuestiones. La Secretaría de Gobernación reconoció en septiembre de 2015 que estaban contabilizados 27.000 desaparecidos y más de 155.000 homicidios dolosos entre 2007 y 2015, de los cuales, según un reporte de Lantia Consultores, un thinktank mexicano especializado en temas de seguridad, al menos 91.406 de esos desaparecidos estarían relacionados con el crimen organizado". Según el mismo medio,

durante el sexenio de Calderón (2006-2012) se detuvo o abatió a 45 líderes de grupos criminales, mientras que la administración Peña Nieto presume 93. Sin embargo, la estrategia de "descabezamiento" seguida por los dos presidentes ha fragmentado al crimen organizado, que pasó de siete a dos grandes cárteles, de Sinaloa y Jalisco Nueva Generación (CJNG) y cientos de células remanentes de organizaciones que ya fueron desmanteladas como Los Zetas, los Caballeros Templarios y Los Beltrán Leyva, entre otros, y ha convertido al país en un territorio en disputa ya no sólo por parte de las bandas del narcotráfico, sino también de quienes secuestran, extorsionan y se dedican a la trata de personas, principalmente mujeres. ${ }^{38}$

Bajo el mandato de Peña Nieto se aprobó un Programa de Seguridad Nacional (20142018) en el que se decía que

al ampliar el concepto de Seguridad Nacional en el diseño de las políticas públicas de nuestro país, se podrán atender problemáticas de naturaleza

\footnotetext{
${ }^{36}$ Secretaría de Gobernación, (2008), "Acuerdo Nacional por la Seguridad, la Justicia y la Legalidad", http://www.oas.org/juridico/spanish/mesicic3 mex anexo24.pdf (Fecha de consulta: 16 de mayo de 2018).

${ }^{37}$ Leticia Robles de Rosa, "Olvidan 19 metas del Acuerdo Nacional por la Seguridad", Excelsior, 29-07-2013, Ciudad de México, México, http://www.excelsior.com.mx/nacional/2013/07/29/911071 (Fecha de consulta: 18 de marzo de 2018).

${ }^{38}$ Juliana Fregoso, "México cumple 10 años de guerra contra el narcotráfico: mucho show, muchos muertos y sin final a la vista", Infobae,4-12-2016, Ciudad México, México, https://www.infobae.com/america/americalatina/2016/12/04/mexico-cumple-10-anos-de-guerra-a-los-narcos-con-mucho-show-muchos-muertos-ysin-final-a-la-vista/(Fecha de consulta: 18 de marzo de 2018).
} 
diversa a las estrictamente relacionadas con actos violentos que vulneran los derechos fundamentales de la población mexicana. Además de cumplir con la obligación del Gobierno de la República de restablecer la tranquilidad y seguridad de los ciudadanos, a través del combate a toda manifestación de violencia y delincuencia de alto impacto, se debe transitar hacia un modelo de Seguridad Nacional más amplio y de justicia e inclusión social, de combate a la pobreza, de educación con calidad, de prevención y atención de enfermedades, de equilibrio ecológico y protección al ambiente, de promoción del desarrollo económico, social y cultural, así como de seguridad en las tecnologías de la información y la comunicación. De este modo, la Seguridad Nacional adquiere un carácter multidimensional que la hace vigente y fortalece el proyecto nacional. ${ }^{39}$

Cuando tomó posesión el actual Presidente, Manuel López Obrador, aseguró que no repetiría los errores del pasado, que no seguiría las estrategias puestas en marcha por sus antecesores, sino que tomaría medidas radicales para acabar con la corrupción existente en los cuerpos de seguridad. También se refirió a la posibilidad de legalizar ciertas drogas, lo que implicaría un profundo cambio de dirección. Como ya se ha dicho, se ha manifestado además en contra del mantenimiento de otras acciones, como la Iniciativa Mérida, y realizado unas declaraciones en las que afirmaba que México ya no estaba en guerra contra el narcotráfico y que el interés y la función del gobierno no era detener capos, sino garantizar la seguridad pública ${ }^{40}$. Evidentemente aún es muy pronto para realizar un balance sobre ello, aunque las cifras disponibles no parecen augurar grandes logros en esta lucha.

\footnotetext{
${ }^{39}$ Consejo de Seguridad Nacional, (2014), “Programa para la Seguridad Nacional 2014 - 2018: Una política multidimensional paraMéxico en el siglo XXI", http://cdn.presidencia.gob.mx/programa-para-la-seguridadnacional.pdf(Fecha de consulta: 18 de marzo de 2018).

${ }^{40}$ CNN Español, "AMLO dice que "oficialmente" México ya no está en guerra contra el narcotráfico", 31-012019, Ciudad de México, México, https://cnnespanol.cnn.com/2019/01/31/amlo-dice-que-oficialmente-mexico-ya-no-esta-en-guerra-contra-el-narcotrafico/(Fecha de consulta: 30 de agosto de 2019).
} 


\section{El narcotráfico como problema social y de derechos humanos ${ }^{41}$}

La posibilidad de que se produzca el desarrollo del narcotráfico como "industria nacional" es la manifestación más clara de la debilidad del estado de derecho en el país de que se trate. Algunos autores se refieren precisamente al hecho de que el cambio de gobierno del PRI al PAN que, si bien trajo cotas de democracia mayores, lo hizo en un país que no estaba preparado para enfrentar la democracia, pues las instituciones llevaban muchos años funcionando bajo reglas propias en las que la corrupción, la alianza con el narcotráfico de las autoridades o la debilidad de los poderes, no había permitido que se consolidaran y funcionaran adecuadamente.

México ha sido tradicionalmente un país en el que las instituciones han sido débiles y nunca han sentido la necesidad de dar cuentas a la sociedad, por lo que han funcionado como entidades propicias a la corrupción y a la molicie, con unos funcionarios en general muy mal pagados y por lo tanto proclives a incrementar sus ingresos de diversas maneras extraoficiales. Por otro lado, la sociedad mexicana también tiene muchas carencias: a lo largo del país existen importantes bolsas de pobreza y exclusión social que no permiten que las comunidades puedan desarrollarse de manera eficaz. Son muchos los jóvenes que no terminan sus estudios y tampoco encuentran un trabajo que les dé suficiente dinero para mantenerse ni para mantener una posible familia. Así,

estas dinámicas de exclusión se encuentran entre las causas de la frustración y la desesperanza de amplios segmentos de la población, especialmente de los jóvenes, a los que ni el sistema educativo, ni el mercado de trabajo les ofrece opciones para integrase en la economía y en la sociedad. Al mismo tiempo que se les incita al consumo, en un contexto en el que ciertas actividades delictivas suponen dinero rápido y una particular forma de afirmación y prestigio social. Además, hay pocos riesgos de que se termine en la cárcel a causa de la ineficacia o la corrupción de la policía y la debilidad del sistema de justicia penal (Mesa Peinado, 2007: 42).

De hecho, al principio de su mandato, el presidente Calderón hizo referencia a la necesidad de que la lucha contra la droga fuese acompañada de una política de creación de empleo y del combate contra la pobreza. El problema es que nunca se realizó realmente, aunque se presentó el Plan Nacional de Desarrollo (CEFP/096/2007), con vigencia entre 2007 y 2012. El esquema que se publicó es el siguiente (Figuras 1$)^{42}$ :

\footnotetext{
${ }^{41}$ En relación con las políticas sociales y los derechos humanos en México, hay obras muy interesantes, como: Félix Acosta (2010), "La evaluación de la política social en México: avances recientes, tareas pendientes y dilemas persistentes", Papeles de población, Toluca,v. 16, pp. 155-188; Sara Núñez de Prado (2018), "Espejos enfrentados: México frente al continente americano y la UE", en Ricardo Martín de la Guardia y Guillermo Pérez Sánchez (eds.), La integración europea e iberoamericana. Actualidad y perspectivas en el siglo XXI, VaIladolid: Thomson Reuters Aranzadi, pp. 325-349; Miguel Ángel de los Santos (2008), “Derechos humanos: compromisos internacionales, obligaciones nacionales", Reforma Judicial. Revista Mexicana de Justicia', Ciudad de México, no 12; Felipe Torres y Agustín Rojas (2015), "Política Económica y Política Social en México: desequilibrio y saldos", Revista Problemas del Desarrollo, Ciudad de México, v. 46, pp. 41-65.

${ }^{42}$ Centro de estudios de las Finanzas Públicas de la Cámara de Diputados, (2007), "PlanNacional de Desarrollo 2007-2012", http://www.cefp.gob.mx/intr/edocumentos/pdf/cefp/cefp0962007.pdf. (Fecha de consulta: 16 de mayo de 2018).
} 
Figura 1. Plan Nacional de Desarrollo 2012-2018

\begin{tabular}{|c|c|}
\hline FIGURA 5 & Plan Nacional de Desarrollo 2007-2012 (Felipe Calderón) \\
\hline \multirow{6}{*}{ Estructura } & 1.-Desarrollo Humano Sustentable \\
\hline & 2. - Estado de Derecho y Seguridad \\
\hline & 3.-Economia competitha y generadora de empleos \\
\hline & 4. Igualdad de oportunidades. \\
\hline & 5. Sustentablidad amblental \\
\hline & 6. Democracia efectiva y politica exterior responsable \\
\hline Visión & $\begin{array}{l}\text { Un México hacía el ah̃o } 2030 \text { con una famillia y patrimonio seguro, un pais de } \\
\text { leyes, economia competitiva, país con desarrollo sustentable y democrática. }\end{array}$ \\
\hline \multirow{10}{*}{ Objetivos } & $\begin{array}{l}\text { 1. Garantizar la seguridad nacional, asegurar la viabilidad del Estado y de la } \\
\text { demacracia. }\end{array}$ \\
\hline & 2. Garantizar la vigencia plena del Estado de Derecho. \\
\hline & 3. Alcanzar un crecimiento sostenido acelerado. \\
\hline & 4. Tener una economia competitiva. \\
\hline & 5. Reducir la pobreza extrema. \\
\hline & 6. Reducir las brechos socicles, economicas y culturales. \\
\hline & 7. Garantizar los derechos de los ciudadanos. \\
\hline & 8. Asegurar la sustentabilidad amblental. \\
\hline & 9. Consolidar un régimen democrático. \\
\hline & 10. Aprovechar los beneficios de un mundo globalizado. \\
\hline \multirow{7}{*}{ Estrategias } & $\begin{array}{l}\text { 1. Piantear una estrategia integral de politica publica, para enfrentar los retos } \\
\text { multinacionales del pais. Además reducir la discrecionalidad de las autoridades } \\
\text { administrativas y judiciales en la aplicación de las normas. }\end{array}$ \\
\hline & $\begin{array}{l}\text { 2. Establecer un Desarrollo Humano Sustentable, logrando la transformación } \\
\text { política del pais. Combatiendo la corrupción a lo largo de todo el proceso de } \\
\text { impartición de justicia. }\end{array}$ \\
\hline & $\begin{array}{l}\text { 3. Fortalecimiento de la comunidad familiar, para fomentar la solidaridad. Sobre } \\
\text { todo mejorar la regulación que protege los derechos de propiedad. }\end{array}$ \\
\hline & $\begin{array}{l}\text { 4. Promover la modemización integral de México. para transformar la cultura } \\
\text { ambiental de nuestrasociedad. }\end{array}$ \\
\hline & $\begin{array}{l}\text { 5. Fomentar condiciones de competencia económica y libre concurrencia, así } \\
\text { como combatir monopolios. Profundizar y facilitar los procesos de investigación } \\
\text { cientifica, adopción e innovación tecnológica, para incrementar la } \\
\text { productividad de la economia nacional. }\end{array}$ \\
\hline & $\begin{array}{l}\text { 6. Converger y oplimizar los programas y recursos, que incrementen las } \\
\text { oportunidades de acceso a servicios en el medio rural y reduzcan la pobreza. }\end{array}$ \\
\hline & $\begin{array}{l}\text { 7. Mejorar la productividad laboral, a través de la organización, capacitación y } \\
\text { asistencia técnica. }\end{array}$ \\
\hline
\end{tabular}

Fuente: Centro de estudios de las Finanzas Públicas de la Cámara de Diputados.

El siguiente Plan, correspondiente al presidente Peña Nieto, está concebido para el periodo 2013-2018. El cuadro resumen que el propio Plan presentaba era el siguiente (figura 2$)^{43}$ :

\footnotetext{
${ }^{43}$ Gobierno de la República, (2013),"Plan Nacional de Desarrollo 2013-2018”, http://www.snieg.mx/contenidos/espanol/normatividad/MarcoJuridico/PND_2013-2018.pdf, (Fecha de consulta: 16 de mayo de 2018).
} 
Figura 2. Esquema del Plan Nacional de Desarrollo 2013-2018

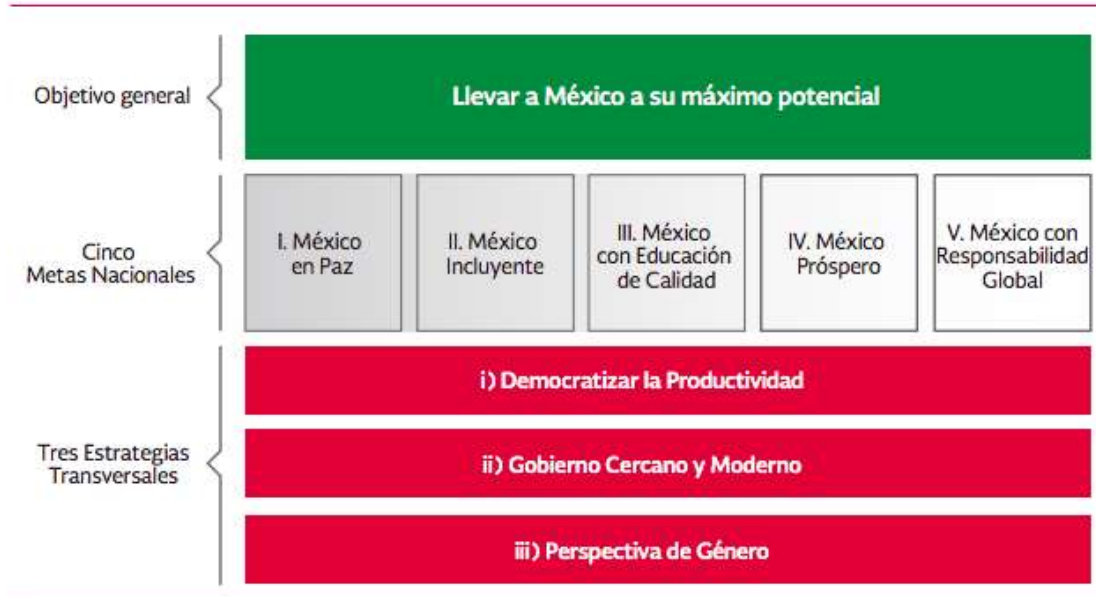

Fuente: Gobierno de la República

El Plan de Desarrollo actual es el correspondiente a 2019-2024 y fue presentado en abril de 2019. Sus puntos fundamentales hacen referencia a los siguientes apartados:

\begin{tabular}{|l|l|}
\hline Política y Gobierno & Erradicar la corrupción, el dispendio y la frivolidad \\
\cline { 2 - 3 } & Recuperar el estado de derecho \\
\cline { 2 - 3 } & Separar el poder político del poder económico \\
\cline { 2 - 3 } & $\begin{array}{l}\text { Cambiar el paradigma en seguridad: Erradicar la corrupción y } \\
\text { reactivar la procuración de justicia; } \\
\text { Garantizar empleo, educación, salud y bienestar; Pleno res- } \\
\text { peto a los derechos humanos; Regeneración ética de las insti- } \\
\text { tuciones y de la sociedad; Reformular el combate a las drogas; } \\
\text { Emprender la construcción de la paz; Recuperación y dignifi- } \\
\text { cación de las cárceles; Articulación de la seguridad nacional, } \\
\text { la seguridad pública y la paz; Reorientación de las Fuerzas Ar- } \\
\text { madas y establecimiento de la Guardia Nacional }\end{array}$ \\
\cline { 2 - 2 } & $\begin{array}{l}\text { Coordinar los distintos niveles de poder: nacional, estatal y } \\
\text { regional }\end{array}$ \\
\hline & Fomento de la democracia participativa \\
\hline
\end{tabular}




\begin{tabular}{|c|c|}
\hline & $\begin{array}{l}\text { Recuperación de los principios en política exterior y solucio- } \\
\text { nar el problema de la migración. }\end{array}$ \\
\hline \multirow[t]{5}{*}{ Política Social } & Construir un país con bienestar \\
\hline & Desarrollo sostenible \\
\hline & Derecho a la educación \\
\hline & Salud para toda la población \\
\hline & Cultura para la paz, para el bienestar y para todos \\
\hline \multirow[t]{11}{*}{ Economía } & Detonar el crecimiento \\
\hline & Mantener finanzas sanas \\
\hline & No más incrementos impositivos \\
\hline & $\begin{array}{l}\text { Respeto a los contratos existentes y aliento a la inversión pri- } \\
\text { vada }\end{array}$ \\
\hline & Rescate del sector energético \\
\hline & $\begin{array}{l}\text { Impulsar la reactivación económica, el mercado interno y el } \\
\text { empleo }\end{array}$ \\
\hline & Creación del Banco del Bienestar \\
\hline & Construcción de caminos rurales \\
\hline & Cobertura de Internet para todo el país \\
\hline & Autosuficiencia alimentaria y rescate del campo \\
\hline & El deporte es salud, cohesión social y orgullo nacional \\
\hline
\end{tabular}

Fuente: Elaboración propia a partir del propio Plan Nacional de Desarrollo 44

En este sentido, han llamado la atención de manera reiterada las declaraciones de López Obrador en el sentido de imponer un plan de pacificación que incluya también amnistía y reconciliación entra las victimas y los victimarios. Esa controversia viene dada, porque otras voces se alzan ante el riesgo claro de que "este gobierno puede terminar con más 154.000 asesinatos" ${ }^{\prime 4}$.

Es muy habitual también que las autoridades mexicanas se escuden en la vecindad con Estados Unidos para justificar que su geografía está infiltrada de narcotraficantes. La explicación más fácil es que, mientras el vecino del Norte no consiga reducir la demanda de drogas, a la vez que las sigue prohibiendo, el narcotráfico en México no desaparecerá. Y si bien existe un importante fondo de verdad en esta afirmación, no es menos cierto que los estadounidenses de lo que no son responsables es de los altos niveles de corrupción existentes en el país azteca y de la realidad de que ya sea el propio narco o personas que le ayudan y colaboraran con los cárteles, están dentro de prácticamente todas las estancias y

\footnotetext{
${ }^{44}$ Gobierno de la República, (2019), "Plan Nacional de Desarrollo 2019-2024", https://lopezobrador.org.mx/wp-content/uploads/2019/05/PLAN-NACIONAL-DE-DESARROLLO-2019-2024.pdf. (Fecha de consulta: 30 de agosto de 2019).

${ }^{45}$ Alberto Najar, “México: la polémica "pacificación" que propone López Obrador para terminar con la cruel guerra del narco en su país", BBC Mundo, 7-8-2018, Ciudad de México, México,

https://www.bbc.com/mundo/noticias-america-latina-45093519.
} 
jerarquías políticas. Ahora bien, no puede dejar de tenerse presente que, desde el inicio del narcotráfico, la escala fundamental de infiltración de los narcos en la política ha sido en los gobiernos locales, realidad que hoy se mantiene inalterable, lo que obviamente debilita a su vez al poder central. Además, tampoco las decisiones que se toman desde el gobierno federal son aceptadas y acatadas por los poderes del Estado o por los municipales, que muchas veces tienen intereses divergentes a los de la Federación, ya sea porque pertenecen a partidos distintos (cuestión que durante las siete décadas de hegemonía del PRI no pasaba) o porque tienen intereses particulares. Consecuencia de ello es que estamos ante un Estado que tiene fragmentada y debilitada su capacidad de poder. Es claro que "la violencia se exacerba sólo bajo ciertas condiciones sociales y políticas, o bajo una configuración particular de las relaciones de poder, cuyos devenir y configuración actual deben ser cartografiados" (Pereyra, 2012: 430). De hecho, cuando el presidente Felipe Calderón inició su programa de lucha contra el narcotráfico, entre las razones que dio fue precisamente la de que los que los traficantes estaban haciéndose con el control territorial del Estado en distintas partes del país y que habían conseguido permear la estructura institucional estatal a unos niveles que habían superado con mucho a épocas anteriores. Eduardo Gamarra, aunque en su estudio se refiere a América Latina en general y especialmente a Colombia, nos recuerda que

la debilidad del estado ha sido interpretada principalmente como la ausencia de instituciones policiales y militares capaces de hacerle frente a la proliferación de la economía ilícita (...) la necesidad de imponer la ley y de expandir los límites de la soberanía del estado debería haber surgido paralelamente con la necesidad de construir una cultura del debido proceso. Se necesitaba un estado fuerte con presencia en todo el territorio nacional, pero a la vez se precisaban agencias de seguridad que gozaran de la confianza ciudadana (Gamarra, 2014: 250).

Hay otra realidad que tampoco se puede obviar, como es el flagelo constante que los derechos humanos están sufriendo desde que el narco subió un escalón en el uso de la violencia y se inició la guerra contra ellos durante la presidencia de Calderón. Desde que empezó la lucha armada, han sido muchos los civiles inocentes que se han convertido en víctimas del narcotráfico y de las fuerzas del orden. También ciertas categorías se han visto especialmente dañadas, como es el caso de los periodistas, muchos de los cuales han pagado con su vida. Según el informe publicado por Reporteros sin Fronteras, México es el país en paz más peligroso del planeta para los periodistas. En 2018 asesinaron a 8 reporteros y a 2 periodistas ciudadanos, y en lo que va del 2019 son ya 9 los informadores asesinados. Se añade, además, que el problema de fondo también es la impunidad en la que quedan estos ataques, ya que el $99,13 \%$ de las agresiones que sufren los informadores quedan sin condena, según datos de la ONG Artículo $19^{46}$.

\footnotetext{
46Jon Martín Cullell, "El desamparo de los periodistas amenazados en México: "Mi muerte tenía fecha”, El País, 12-08-2019, Ciudad de México, México, https://elpais.com/sociedad/2019/08/11/actualidad/1565520706 580649.html(Fecha de consulta: 30 de agosto de 2019).
} 
Las torturas a los detenidos para obtener información también han sido una realidad cotidiana, tanto la infligida por los grupos narcos armados, como los Zetas ${ }^{47}$, uno de los más violentos, como por el ejército y la policía.

Para acabar este apartado, se ha criticado mucho la política emprendida por el presidente Calderón en relación con el narcotráfico. Diversos analistas y periodistas han llegado a decir que si la violencia se incrementó fue precisamente como consecuencia de dicha política y de haber utilizado el ejército en la lucha contra los narcos. También se ha dicho que esa guerra puesta en marcha contra la droga no podía triunfar, porque era meramente ofensiva y no estaba acompañada de otra de tipo preventivo. Desde nuestro punto de vista, si bien compartimos la afirmación de que el despliegue de fuerzas debía estar acompañado de una política general de cambio, desarrollo y fortalecimiento de la democracia, en lo que diferimos es en que ello no haya sido así. A lo largo del trabajo hemos visto cómo el presidente Calderón en diversas intervenciones se refirió precisamente a esta necesidad y era consciente de ella. Lo que creemos que pasó es que así como el poder estaba debilitado para luchar contra el narcotráfico, también lo estaba para imponer unas estrategias determinadas en todo el territorio nacional y tampoco podía librarse fácilmente de los vínculos entre la clase política y los cárteles, en el caso de que hubiera verdadero interés en hacerlo. El apoyo obtenido de los poderes estatales y municipales muchas veces era más de imagen que de realidad. Así, la fragmentación del poder se hizo notar en todos los aspectos de la política, no sólo en el de la lucha armada contra el narco. Por otro lado, y sin entrar a juzgar la capacidad de gobierno y la inteligencia para gobernar del presidente Calderón, lo que sí hay que reconocerle es la valentía de intentar romper una dinámica que hasta ese momento nadie había tenido. El problema es que, después de décadas de desarrollo paralelo entre el poder político y el del narco, este último tenía sus propias dinámicas de evolución. Dinámicas que, desgraciadamente, el presidente Calderón no fue capaz de entender y de revertir. El resultado: México se desangró.

\section{Breve panorama actual}

Probablemente estemos entrando en una nueva etapa, debido a una serie de cambios que se están produciendo en la forma de actuar de los narcos y también en la manera en la que parece encarar el problema el gobierno actual. En relación con los narcos, el hecho es que, aunque la tendencia comenzó hace algunos años, últimamente se están "interesando" por otro tipo de actividades paralelas, como es la producción agrícola o sobre todo cuestiones relacionadas con el robo y tráfico ilegal de combustible, así como también otras relacionadas con la extracción minera, que se comenzó ya iniciado este siglo. Esta última se hace de manera ilegal e igualmente se exporta al extranjero, a países como China.

Los cárteles que comenzaron con estas actividades parece que fueron el de Los Zetas, que estaba perdiendo poder en el mundo del narcotráfico en los últimos años y el de los Caballeros Templarios, hoy prácticamente desaparecido. Pero hay otros, como la Familia Michoacana.

\footnotetext{
${ }^{47}$ Este grupo se formó con personal procedente de los cuerpos del ejército, incluso de los cuerpos de élite, como el Grupo Aeromóvil de Fuerzas Especiales (GAFES), muchos de cuyos miembros fueron entrenados en Estados Unidos.
} 
La entrada en este negocio se ha hecho de distintas formas, desde la extorsión a los directores de las minas o el pago por "seguridad", pasando por la exigencia de que el mineral se transporte en vehículos de propiedad de los cárteles, hasta la explotación directa ilegal y la exportación al extranjero o incluso la venta a organismos nacionales del mineral ilegalmente extraído. Para entender esta actividad hay que tener en cuenta que la explotación mineral, así como los hidrocarburos y otras fuentes de energía, pertenecen al estado, que es el que fija las cuotas de extracción en función de las necesidades y también quien da la licencias para el comercio. Y esta situación no sólo afecta a los mexicanos, sino que también está teniendo consecuencias para las multinacionales que explotan determinadas minas con, por ejemplo, una muy difícil extracción. Estas empresas, que son fundamentalmente estadounidenses y canadienses, obtuvieron sus licencias al amparo del TLCAN. El proceso con la cuestión del petróleo ha sido similar. Además, la reforma energética de Peña Nieto, que elevó los precios del crudo, permitió a estos nuevos huachicoleros (personas que roban y venden combustible) ofrecer a precio más bajo el combustible robado. La razón de este giro en los negocios de los narcos hay que buscarla en la presión a la que desde 2006 el gobierno mexicano sometió a los líderes de los cárteles, que si bien, como hemos visto, no sirvió para controlar la seguridad, ni tampoco para acabar con el negocio, sí dificultó sus actividades, empujándolos a encontrar nuevas vías de hacer dinero fácil y rápido.

Además, se está entrando en una nueva dinámica en la que la violencia extrema, sin desaparecer, está cediendo en beneficio de una forma diferente, "más profesional" e incluso más propagandística de llevar el negocio. Una razón para este cambio puede encontrarse en el hecho de que ya está empezando a despuntar una nueva generación de capos que, si bien no tienen todo el poder, sí empiezan a adquirir importantes responsabilidades. Son los hijos de los grandes nombres como El Chapo Guzmán, Rafael Caro Quintero o Félix Arellano, quienes lideraron los cárteles de Sinaloa, el de Guadalajara y el de Tijuana, respectivamente. Esta nueva generación no es personal de segunda que tiene que demostrar su capacidad de mando, sino que ha heredado el control por derecho de sangre. También han estudiado en los mejores centros escolares del país y han entrado desde niños en un mundo muy distinto al que conocieron sus padres, lo que les ha proporcionado una visión diferente de las cosas. $\mathrm{Y}$ todo ello les ha hecho enfrentar el negocio desde una perspectiva distinta.

\section{Conclusiones}

México está caracterizado por una realidad dual que no puede dejar de tenerse en cuenta a la hora de realizar cualquier análisis, tanto de política interna como externa. Por un lado, es un mercado muy preparado, orientado a una economía global y con altas posibilidades de competir en igualdad de condiciones, con otros países de características similares al mexicano. En este sentido, es un socio deseable e importante al que hay que conservar. Sin embargo, en la otra cara de la moneda, encontramos un país lastrado por el narcotráfico y la violencia, con altos niveles de corrupción y con tasas de desempleo que van en aumento, igual que las desigualdades sociales, que en lugar de reducirse se van haciendo cada vez mayores.

Internamente tiene "asignaturas pendientes" que no ha resuelto nunca y que parece incapaz de resolver. Ha progresado mucho en cuestiones de legislación, siendo en este sentido un país avanzado en todo lo relativo a legislación social, de derechos humanos, etc. 
Pero esto choca con una realidad que nada tiene que ver ni con la letra ni con el espíritu de las leyes que lo rigen. No sólo es el tema de la violencia, sino que a éste se acompaña otro, como mínimo igual de importante, que es el de la impunidad de los crímenes que se cometen. $Y$ a ello se añade el hecho de que la seguridad jurídica no es algo que caracterice al sistema judicial mexicano. La violencia y la impunidad son dos de los grandes problemas a los que se enfrenta el estado azteca, pero que hay que tener en cuenta que están relacionado con otros, como la corrupción.

El tema de la corrupción es endémico en México y afecta, sin distinción, a todas las capas sociales y está inserto en todos los aspectos. No son sólo las autoridades que colaboran de una u otra manera con el narcotráfico, sino que va mucho más allá y está incrustado en lo que podría denominarse "la cultura de hacer las cosas fáciles". Cierto es que las autoridades han introducido muchos controles encaminados a vigilar, por ejemplo, el blanqueo de capitales o la evasión de impuestos. Y cierto es también que se han aprobado normas enfocadas a castigar ciertas prácticas y que en diferentes ocasiones se ha condenado a los corruptos. No obstante, nunca ha sido suficiente y tampoco se ha puesto en marcha un intento de reeducación o culturización que penetre en las distintas capas sociales. Así, se han dificultado muchas transacciones, pero otras siguen realizándose de la misma manera que siempre. De ahí, que sea un problema de muy difícil solución, ya que va más allá de la legislación o la práctica policial - y ello sin entrar en el análisis de hasta dónde llegan dichas prácticas corruptas. Como se ha visto, en distintos momentos históricos han sido muchos los rumores y las evidencias de que esta lacra llegaba hasta las más altas instancias del estado. Es una realidad que existe una clara relación en el ámbito mexicano entre narcotráfico y democracia, de igual manera que existe entre narcotráfico y economía y entre economía y democracia.

Otra cuestión que se ha repetido hasta la saciedad es que la lucha violenta contra el narco solo genera más violencia. La táctica de debilitar un cártel a costa del beneficio del otro tampoco ha funcionado. El combate por los territorios y sobre todo por el control de las rutas de paso es cada vez más feroz. La batalla ha de ser de la policía e incluso del ejército, a pesar de las diferencias existentes entre estos dos cuerpos, pero para que esta lucha tenga resultados mejores que los hasta ahora obtenidos, ha de estar acompañada de toda una serie de medidas de reforma políticas, sociales y económicas. En el caso de México, hay que reestructurar primero los cuerpos armados en profundidad. Al mismo tiempo, también debe cambiarse el sistema de justicia, con el fin de pasar de una justicia disfuncional a otra efectiva, ágil y sobre todo libre de corrupción. Entre las medidas económicas y sociales, hay que conseguir una mejor redistribución de la riqueza que evite la formación de importantes bolsas de marginación que, como ya hemos dicho, son el lugar ideal para el reclutamiento de personas que trabajen para los carteles de la droga. En estados como Michoacán o Jalisco, se pueden encontrar pueblos enteros en los que el recurso económico es exclusivamente el que proporciona la droga.

Es fundamental, por tanto, que se regenere la democracia, que el pueblo pueda volver a tener confianza en sus instituciones y en sus fuerzas de seguridad. Los partidos políticos, las procuradurías, los jueces, la policía, el ejército.... en definitiva, la democracia y las instituciones han perdido legitimidad ante los ciudadanos, quienes piensan que la mayoría de los políticos y funcionarios están vendidos al mundo del narco. 
En definitiva y para cerrar, México se enfrenta a grandes y graves problemas que no son de ahora, sino que devienen de muy lejos, arraigados en una cultura que se ha ido gestando desde la Revolución hasta hoy, por lo que la dificultad de hacerles frente es muy alta. Probablemente habrán de pasar generaciones para que la alternancia de los partidos en el poder, si sigue produciéndose ésta, sirva para cambiar la cultura de partido único y democracia simulada que ha existido durante más de siete décadas. Si se consigue avanzar hacia una democracia real y sobre todo si el poder federal, apoyándose en los estatales y municipales, logra recuperar la autoridad efectiva en todo el territorio, cuestiones como las relaciones del poder con el narcotráfico, la impunidad ante los crímenes, la violencia y los problemas sociales podrían ir poco a poco menguándose.

México es un país con suficiente riqueza propia, con un mercado sólido, una población trabajadora y una economía abierta. Además, es miembro de las organizaciones internacionales más importantes, con un papel en la sociedad internacional a ser tenido en cuenta y con unas relaciones políticas que le hacen ser un actor de primer orden en el concierto mundial. Las autoridades deben racionalizar los esfuerzos e ir implantando una cultura de la democracia que consiga extenderse por toda la República y que facilite que el país azteca solucione sus problemas internos. El riesgo de no hacerlo es convertirse en un estado lastrado por la corrupción y el narcotráfico y al final del camino, en un Estado fallido.

\section{Bibliografía}

\section{Fuentes primarias}

Centro de estudios de las Finanzas Públicas de la Cámara de Diputados, (2007), "PlanNacional de Desarrollo 2007-2012", http://www.cefp.gob.mx/intr/edocumentos/pdf/cefp/cefp0962007.pdf.

Drug Enforcement Administration (DEA), (2015), "National Drug Threat Assessment", https://www.dea.gov/docs/2015\%20NDTA\%20Report.pdf.

Embajada y Consulados de Estados Unidos en México, (2018), "Iniciativa Mérida", https://mx.usembassy.gov/es/our-relationship-es/temas-bilaterales/iniciativamerida/.

Gobierno de la República, (2013), "Plan Nacional de Desarrollo 2013-2018”, http://www.snieg.mx/contenidos/espanol/normatividad/MarcoJuridico/PND 2013-2018.pdf.

Presidencia de la República, (2016), “Anuncio sobre la Operación Michoacán”, http://calderon.presidencia.gob.mx/2006/12/anuncio-sobre-la-operacion-conjunta-michoacan/.

Gobierno de la República, (2019), "Plan Nacional de Desarrollo 2019-2024", https://lopezobrador.org.mx/wp-content/uploads/2019/05/PLAN-NACIONAL-DE-DESARROLLO-2019-2024.pdf,

Secretaría de Gobernación, (2008), "Acuerdo Nacional por la Seguridad, la Justicia y la Legalidad", http://www.oas.org/juridico/spanish/mesicic3 mex anexo24.pdf.

United Nations Office on Drugs and Crime, (2019), "World Drug Report", 
https://wdr.unodc.org/wdr2019/en/index.html.

\section{Publicaciones periódicas}

Arsinoé Orihuela Ochoa, "México. La otra historia del narcotráfico (I)", Tercera Información, Madrid, España. 5-12-2017, http://www.tercerainformacion.es/opinion/opinion/2017/12/05/mexico-la-otra-historia-del-narcotrafico-i

Alberto Najar, "México: la polémica "pacificación" que propone López Obrador para terminar con la cruel guerra del narco en su país", BBC Mundo, 7-8-2018, Ciudad de México, México,https://www.bbc.com/mundo/noticias-america-latina-45093519

Carmen Merino, “Drogas: ¿Sabes cuánto dinero mueve el narcotráfico en el mundo?”, La República, 4-11-2018, Lima, Perú, https://larepublica.pe/economia/1350878narcotrafico-dinero-mueve-mundo.

CNN Español, "AMLO dice que "oficialmente” México ya no está en guerra contra el narcotráfico", 31-01-2019, Ciudad de México, México, https://cnnespanol.cnn.com/2019/01/31/amlo-dice-que-oficialmente-mexico-ya-no-esta-enguerra-contra-el-narcotrafico/.

Elías Camhaji, Jacobo García, “Año 11: la guerra contra el Narco”,El País,22-01-2018, Ciudad de México, México,https://elpais.com/especiales/2016/guerra-narcotraficomexico/.

Enrique Florescano (Ed.), “La Operación Cóndor. Recuento mínimo”, Nexos, 1-05-1978, Ciudad de México, México, https://www.nexos.com.mx/?p=3120

Excelsior, "Mario Villanueva Madrid, los delitos que lo llevaron a prisión”, 16-01-2017, Ciudad de México, México, http://www.excelsior.com.mx/nacional/2017/01/16/1139886

Expansión, "10 años de la iniciativa Mérida: Un recuento de la cooperación entre México y EEUU", 4-09-2017, Ciudad de México, México, http://expansion.mx/nacional/2017/04/09/10-anos-de-la-iniciativa-merida-un-recuento-de-la-cooperacion-entre-mexico-y-eu

Guillermo de la Dehesa, “El gran negocio del narcotráfico", El País, 9-02-2018, Madrid, España, https://elpais.com/economia/2018/02/08/actualidad/1518088355_153674.html

Ignacio Alzaga, "Juez ordena indemnizar a familiares de 'Kiki' Camarena", Milenio, 13-012017, Monterrey, México, http://www.milenio.com/policia/kiki-camarenadon-neto-asesinato-dea-agente-asesinado-cartel guadalajara 0 883711836.html.

Jon Martín Cullell, "El desamparo de los periodistas amenazados en México: "Mi muerte tenía fecha", El País, 12-08-2019, Ciudad de México, México, https://elpais.com/sociedad/2019/08/11/actualidad/1565520706 580649.html.

Jorge Alejandro Medellín, "México rechaza continuar con la Iniciativa Mérida de apoyo norteamericano contra el narcotráfico", 31-05-2019, Defensa.com, Ciudad de México, México,https://www.defensa.com/mexico/mexico-rechaza-continuariniciativa-merida-apoyo-norteamericano. 
Juliana Fregoso, "México cumple 10 años de guerra contra el narcotráfico: mucho show, muchos muertos y sin final a la vista", Infobae, 4-12-2016, Ciudad México, México, https://www.infobae.com/america/america-latina/2016/12/04/mexicocumple-10-anos-de-guerra-a-los-narcos-con-mucho-show-muchos-muertos-ysin-final-a-la-vista/.

Leticia Robles de Rosa, "Olvidan 19 metas del Acuerdo Nacional por la Seguridad", Excelsior, 29-07-2013, Ciudad de México, México, http://www.excelsior.com.mx/nacio$\underline{\mathrm{nal} / 2013 / 07 / 29 / 911071}$

Luis Prados, "Moisés Naím advierte contra las "cinco guerras de la globalización"”, El País, 225-2003, Madrid, España,https://elpais.com/diario/2003/05/22/internacional/1053554419 850215.html.

Nidia Marín, “Operación Cóndor, el inicio de la guerra contra el narcotráfico ", El Sol de México, 24-04-2016, Ciudad de México, México, https://www.elsoldemexico.com.mx/mexico/Operaci\%C3\%B3nC\%C3\%B3ndor-el-inicio-de-la-guerra-contra-el-narcotr\%C3\%A1fico170670.html

Noticieros Televisa, “Las fugas de Joaquín ‘El Chapo' Guzmán”, Televisa, 19-01-2017, Ciudad de México, México, http://noticieros.televisa.com/historia/nacional/2017-0119/las-fugas-de-joaquin-el-chapo-guzman/.

\section{Fuentes Secundarias}

Carlos Alberto Anglés Zamudio (2011), México y su ley contra el narcomenudeo, Londres: Internacional DrugPolicyConsortium.

David Held (1997), La Democracia y el orden global. Del estado moderno al gobierno cosmopolita. Barcelona: Paidós.

Eduardo Gamarra (2014), "La democracia y las drogas en América Latina y el Caribe”, en PNUD-NNUU (eds.), La democracia en América Latina. Hacia una democracia de ciudadanos y ciudadanas. Contribuciones para el debate, Buenos Aires: Aguilar, Altea, Taurus, Alfaguara, 245-258.

Enrique Peña Nieto (2016), Reforma Penal 2008-2016. El Sistema Penal Acusatorio en México. Ciudad de México: Instituto Nacional de Ciencias Penales (INACIPE).

Guillermo Pereyra (2012), "México: violencia criminal y "guerra contra el narcotráfico", $R e$ vista Mexicana de Sociología, Ciudad de México, v. 74, pp. 429-460.

Laurie Freeman (2006), Estado bajo asalto. La narcoviolencia y la corrupción en México. Washington D.C.: WOLA.

Manuela Mesa Peinado (2008), “Globalización y violencia transnacional: dinámicas, costes y propuestas", en Manuela Mesa Peinado (eds.), Paz y conflictos en el siglo XXI. Anuario 2007-2008, CEIPAZ-Fundación Cultura de Paz, Madrid: Centro de Educación e investigación para la paz, pp. 39-61. 